\title{
Frequency of MCR-1-mediated colistin resistance among Escherichia coli clinical isolates obtained from patients in Canadian hospitals (CANWARD 2008-2015)
}

\author{
Andrew Walkty MD, James A. Karlowsky PhD, Heather J. Adam PhD, Philippe Lagacé-Wiens MD, \\ Melanie Baxter MSc, Michael R. Mulvey PhD, Melissa McCracken MSc, Susan M. Poutanen MD, \\ Diane Roscoe MD, George G. Zhanel PhD
}

\section{Abstract}

Background: Colistin is often used as an antimicrobial of last resort for the treatment of infections caused by multidrug-resistant gram-negative bacilli. In 2015, plasmid-mediated colistin resistance in Escherichia coli due to MCR-1 was described. The purpose of this study was to evaluate the frequency of colistin resistance among $E$. coli clinical isolates obtained from patients in Canadian hospitals as part of the Canadian Ward Surveillance Study (CANWARD) and to determine how often the mcr-1 gene is detected among the colistin-resistant subset.

Methods: From January 2008 to December 2015 (excluding 2011), 10 to 15 sentinel hospitals submitted consecutive clinical isolates (1 per patient per infection site) from blood (100-240), respiratory (100-150), urine (25-100) and wound (25-100) infections. We performed susceptibility testing using Clinical and Laboratory Standards Institute broth microdilution methods. Isolates that showed resistance to colistin as defined by European Committee on Antimicrobial Susceptibility Testing breakpoints (minimum inhibitory concentration $\geq 4 \mu \mathrm{g} / \mathrm{mL}$ ) were evaluated for the $\mathrm{mcr}-1$ gene by polymerase chain reaction.

Results: In total, 5571 E. coli clinical isolates were obtained over the study years. Twelve isolates $(0.2 \%)$ were resistant to colistin. The proportion of colistin-resistant isolates varied from $0.0 \%$ to $0.5 \%$ depending on the study year, and there was no clear trend toward increasing resistance over time. Typically the colistin-resistant isolates remained susceptible to antimicrobials from several other classes. Two colistin-resistant isolates (0.04\%) were found to harbour the $\mathrm{mcr}-1$ gene.

Interpretation: The results suggest that colistin resistance among E. coli human clinical isolates, including resistance mediated by the $m c r-1$ gene, remains rare in Canada.

olistin (polymyxin E) is a polypeptide antimicrobial that was originally discovered in $1949 .{ }^{1,2}$ It is capable of binding to lipopolysaccharide molecules in the outer membrane of gram-negative bacteria by displacing calcium and magnesium. This results in changes in cell membrane permeability, leakage of cell contents and, subsequently, cell death. ${ }^{1,2}$ Colistin shows in-vitro activity against a diverse spectrum of clinically important gram-negative bacteria, including many members of the family Enterobacteriaceae and Pseudomonas aeruginosa. ${ }^{1}$ Owing to concerns about toxicity (particularly nephrotoxicity), the use of colistin was largely abandoned by the early 1980s in favour of safer alternatives. ${ }^{1,2}$ However, there has been renewed interest in the use of colistin as an antimicrobial of last resort for the treatment of infections due to multidrug-resistant gram-negative bacteria. ${ }^{2}$ Colistin is often one of the only remaining antimicrobials with in-vitro activity against multidrug-resistant
Enterobacteriaceae, including those that produce carbapenemase enzymes such as the Klebsiella pneumoniae carbapenemase and New Delhi metallo- $\beta$-lactamase.,

In-vitro resistance to colistin commonly involves chromosomal mutations. ${ }^{5,6}$ It frequently results from modifications of the lipid A moiety of lipopolysaccharide, mediated by alterations in the 2-component regulatory systems $\mathrm{PmrA} / \mathrm{PmrB}$ and PhoP/PhoQ.5,6 In 2016, Liu and colleagues ${ }^{7}$ described Escherichia coli isolates with plasmid-mediated colistin resistance due

Competing interests: Philippe Lagacé-Wiens received personal fees from Merck and Sunovion Pharmaceuticals outside the submitted work.

This article has been peer reviewed.

Correspondence to: Andrew Walkty, AWalkty@dsmanitoba.ca

CMAJ Open 2016. DOI:10.9778/cmajo.20160080 
to MCR-1. MCR-1 (encoded for by the $m c r-1$ gene) is a member of the phosphoethanolamine transferase enzyme family. It confers resistance to colistin by the transfer of phosphoethanolamine to lipid A, thereby reducing the affinity of the target (by reducing the negative charge) for this polycationic antimicrobial. $^{7}$ E. coli isolates with the $m c r-1$ gene typically have colistin minimum inhibitory concentrations (MICs) in the range of 4 to $8 \mu \mathrm{g} / \mathrm{mL}^{.711}$

The location of the mor-1 gene on a plasmid is concerning, as this raises the possibility that the resistance determinant may be transferred to multidrug-resistant gram-negative bacteria. Indeed, the $m c r-1$ gene has already been detected in multidrugresistant $E$. coli isolates that also contain an extended-spectrum $\beta$-lactamase or a carbapenemase enzyme. ${ }^{12-15}$ Plasmid-mediated colistin resistance attributed to a second $m c r$ gene $(m c r-2)$ has also recently been described. ${ }^{16}$

Many clinical microbiology laboratories do not test colistin routinely against $E$. coli, so the frequency with which resistance occurs in Canada is difficult to estimate from local data. The purpose of this study was to evaluate the frequency of colistin resistance among $E$. coli clinical isolates obtained from patients in Canadian hospitals as part of a national surveillance study, CANWARD (the Canadian Ward Surveillance Study), and to determine how often the $m c r-1$ gene is detected among the colistin-resistant subset.

\section{Methods}

\section{Bacterial isolates}

From January 2008 to December 2015, as part of CANWARD, sentinel tertiary hospital laboratories across Canada submitted clinical isolates from patients attending emergency departments, medical and surgical wards, hospital clinics and intensive care units. The number of laboratories participating in the study annually varied between 10 and 15 . The hospital laboratories were distributed by population density, with 4 laboratories in western Canada (British Columbia, Alberta, Saskatchewan and Manitoba), 9 in central Canada (Ontario and Quebec), and 2 in eastern Canada (New Brunswick and Nova Scotia). The centres were asked to submit consecutive clinical isolates (1 per patient per infection site) from blood (100-240), respiratory $(100-150)$, urine $(25-100)$ and wound (25-100) infections yearly. The medical centres submitted clinically significant isolates, as defined by their local site criteria. Isolate identification was performed by the submitting site and was confirmed at the reference site as required (i.e., when morphological characteristics and antimicrobial susceptibility patterns did not fit the reported identification). Isolates were shipped on Amies semisolid transport medium to the coordinating laboratory (Health Sciences Centre, Winnipeg), subcultured onto appropriate media and stocked in skim milk at $-80^{\circ} \mathrm{C}$ until MIC testing was carried out. Isolates from 2011 were excluded from the analysis as colistin was not included on the panels used for susceptibility testing during that year. All E. coli isolates obtained from the CANWARD study from 2008 to 2015 (excluding 2011) were included in this analysis.

\section{Antimicrobial susceptibilities}

Following 2 subcultures from frozen stock, we determined the in-vitro activity of antimicrobials commonly used for the treatment of Enterobacteriaceae by broth microdilution in accordance with the Clinical and Laboratory Standards Institute (CLSI) guidelines. ${ }^{17}$ The broth microdilution method used to determine colistin MIC was consistent with recommendations of the joint CLSI-European Committee on Antimicrobial Susceptibility Testing Polymyxin Breakpoints Working group. ${ }^{18}$ Custom broth microdilution panels were prepared on site at the Health Sciences Centre. We interpreted antimicrobial MICs according to current CLSI breakpoints. ${ }^{19} \mathrm{We}$ used European Committee on Antimicrobial Susceptibility Testing breakpoints for interpretation of colistin MICs, as the CLSI has not defined colistin breakpoints for the Enterobacteriaceae. ${ }^{20} \mathrm{We}$ performed quality control for MIC testing in accordance with CLSI recommendations using 2 strains, E. coli ATCC 25922 and P. aeruginosa ATCC 27853. All isolates that tested resistant to colistin as defined by the European Committee on Antimicrobial Susceptibility Testing (MIC $\geq 4 \mu \mathrm{g} / \mathrm{mL}$ ) were submitted to Canada's National Microbiology Laboratory for assessment for the presence of the $m c r-1$ and $m c r-2$ genes.

\section{Detection of $\mathrm{mcr}-1$ and $\mathrm{mcr}-2$}

We screened isolates for the presence of $m o r-1$ using the polymerase chain reaction technique with the primers CLR5-F $\left(5^{\prime} \text {-CGGTCAGTCCGTTTGTTC- }{ }^{\prime}\right)^{7}$ and MCR1-R (5'-ATACACGGCACAGAATACGC-3') (designed in house). We detected the $m c r-2$ gene using the polymerase chain reaction technique as previously described. ${ }^{16}$

\section{Whole genome sequencing and analysis}

We sequenced the $m c r-1$-containing isolates using the Illumina MiSeq platform. The sequences were assembled and analyzed as previously described. ${ }^{21}$ Multilocus sequence type analysis and identification of $m c r-1$ and $m c r-2$ alleles were performed with the use of the Center for Genomic Epidemiology analysis tools (www.genomicepidemiology.org).

\section{Results}

In total, $5571 \mathrm{E}$. coli clinical isolates were obtained as part of the CANWARD study between 2008 and 2015 (excluding 2011). The hospital location of the patients from which the isolates were collected was as follows: emergency department 2095 (37.6\%), medical ward 1674 (30.0\%), clinic 917 (16.5\%), intensive care unit $536(9.6 \%)$ and surgical ward $348(6.2 \%)$; in 1 case $(0.02 \%)$, the location was not specified. The isolates were obtained from the bloodstream (2867 isolates [51.5\%]), urine $(2014[36.2 \%])$, respiratory tract $(481[8.6 \%])$ and wounds (209 [3.8\%]).

Twelve colistin-resistant $E$. coli isolates were recovered, from patients in 4 of the 10 Canadian provinces (British Columbia, Ontario, Quebec and New Brunswick). Five (42\%) of these isolates were recovered from outpatients (clinic or emergency department), and 7 (58\%) were recovered from inpatients 
(intensive care unit or medical ward). Ten (83\%) of the colistinresistant isolates were from a bloodstream source. Seven isolates had a colistin MIC of $4 \mu \mathrm{g} / \mathrm{mL}, 4$ isolates had a colistin MIC of $8 \mu \mathrm{g} / \mathrm{mL}$, and 1 isolate had a colistin MIC of $16 \mu \mathrm{g} / \mathrm{mL}$. The proportion of $E$. coli isolates that tested resistant to colistin, stratified by study year, is presented in Table 1. A total of $0.0 \%-0.5 \%$ of isolates were colistin-resistant each year. There was no clear trend toward increasing colistin resistance among the $E$. coli clinical isolates over the course of the study.

The antimicrobial susceptibility of all isolates and the colistin-resistant subset is presented in Table 2. In general, the colistin-resistant $E$. coli isolates remained susceptible to antimicrobials from a number of different classes. One isolate (8\%) was multidrug-resistant (Table 3, Ontario isolate), as defined by the Canadian Public Health Laboratory Network Antimicrobial Resistance Working Group. ${ }^{22}$ No colistin-resistant isolate was extensively drug-resistant or pan-drug-resistant. ${ }^{22}$

Of the 12 colistin-resistant $E$. coli isolates, only 2 tested positive for the $m c r-1$ gene, and the $m c r-2$ gene was not detected in any of the isolates. The first $m c r-1$-positive isolate was obtained in 2010 from the bloodstream of a male patient assessed at an emergency department in Ontario. The isolate had a colistin MIC of $16 \mu \mathrm{g} / \mathrm{mL}$ and a sequence type of ST648. The second $m c r-1$-positive isolate was obtained in 2010 from the bloodstream of a male patient seen at an emergency department in British Columbia. The colistin MIC for this isolate was $4 \mu \mathrm{g} / \mathrm{mL}$, and the sequence type was ST515. The antimicrobial susceptibility profile of the 2 isolates is presented in Table 3. The isolate from Ontario was multidrugresistant. However, it remained susceptible to broad-spectrum $\beta$-lactams, including third-generation cephalosporins, piperacillin-tazobactam and meropenem. The isolate from British Columbia was susceptible to antimicrobials from multiple different classes. Additional clinical details of the patients from whom the isolates were obtained were not available, and it is not known whether either patient had a history of travel

\begin{tabular}{|c|c|c|c|c|c|}
\hline Year & $\begin{array}{l}\text { No. of } \\
\text { isolates }\end{array}$ & $\begin{array}{c}\text { Colistin } \mathrm{MIC}_{50},{ }^{*} \\
\mu \mathrm{g} / \mathrm{mL}\end{array}$ & $\begin{array}{c}\text { Colistin } \mathrm{MIC}_{90}, \dagger \\
\mu \mathrm{g} / \mathrm{mL}\end{array}$ & $\%$ susceptibleł & \% resistantł \\
\hline 2008 & 1130 & 0.5 & 1.0 & $99.9(1129 / 1130)$ & $0.1(1 / 1130)$ \\
\hline 2009 & 1097 & 0.25 & 0.5 & $99.9(1096 / 1097)$ & $0.1(1 / 1097)$ \\
\hline 2010 & 1013 & 0.25 & 0.5 & $99.5(1008 / 1013)$ & $0.5(5 / 1013)$ \\
\hline 2012 & 499 & 0.25 & 0.5 & $100.0(499 / 499)$ & $0.0(0 / 499)$ \\
\hline 2013 & 655 & 0.25 & 0.5 & $99.7(653 / 655)$ & $0.3(2 / 655)$ \\
\hline 2014 & 618 & 0.25 & 0.5 & $100.0(618 / 618)$ & $0.0(0 / 618)$ \\
\hline 2015 & 559 & 0.25 & 0.5 & $99.5(556 / 559)$ & $0.5(3 / 559)$ \\
\hline \multicolumn{6}{|c|}{$\begin{array}{l}\text { Note: MIC = minimum inhibitory concentration. } \\
{ }^{*} \mathrm{MIC} \text { at or below which } 50 \% \text { of isolates are inhibited. } \\
\text { †MIC at or below which } 90 \% \text { of isolates are inhibited. } \\
\text { fEuropean Committee on Antimicrobial Susceptibility Testing breakpoints for colistin v. Enterobacteriaceae: an MIC of } 2 \mu \mathrm{g} / \mathrm{mL} \text { or les } \\
\text { is defined as susceptible; an MIC of } 4 \mu \mathrm{g} / \mathrm{mL} \text { or more is defined as resistant. }{ }^{20}\end{array}$} \\
\hline
\end{tabular}

Table 2: Antimicrobial susceptibility profile of Escherichia coli isolates recovered from patients in Canadian hospitals as part of the CANWARD study

\begin{tabular}{|c|c|c|c|c|c|c|}
\hline \multirow[b]{2}{*}{ Antimicrobial } & \multicolumn{3}{|c|}{$\begin{array}{l}\text { All isolates } \\
(n=5571)\end{array}$} & \multicolumn{3}{|c|}{$\begin{array}{l}\text { Colistin-resistant subset } \\
\qquad(n=12)\end{array}$} \\
\hline & $\begin{array}{l}\mathrm{MIC}_{50} \\
\mu \mathrm{g} / \mathrm{mL}\end{array}$ & $\begin{array}{l}\mathrm{MIC}_{90}, \\
\mu \mathrm{g} / \mathrm{mL}\end{array}$ & $\%$ susceptible & $\begin{array}{l}\mathrm{MIC}_{50} \\
\mu \mathrm{g} / \mathrm{mL}\end{array}$ & $\begin{array}{l}\mathrm{MIC}_{90} \\
\mu \mathrm{g} / \mathrm{mL}\end{array}$ & $\%$ susceptible \\
\hline Amoxicillin-clavulanate & 4 & 16 & $85.8(4783 / 5571)$ & 4 & 8 & $91.7(11 / 12)$ \\
\hline Cefazolin & 2 & 32 & $71.2(3967 / 5571)$ & 2 & 8 & $75.0(9 / 12)$ \\
\hline Ceftazidime & $\leq 0.5$ & 1 & $94.0(5238 / 5571)$ & $\leq 0.25$ & 0.5 & $100.0(12 / 12)$ \\
\hline Ceftriaxone & $\leq 0.25$ & 0.5 & $91.7(5109 / 5571)$ & $\leq 0.25$ & $\leq 0.25$ & $100.0(12 / 12)$ \\
\hline Ciprofloxacin & $\leq 0.06$ & $>16$ & $76.7(4274 / 5571)$ & $\leq 0.06$ & $>16$ & $75.0(9 / 12)$ \\
\hline Colistin & 0.25 & 0.5 & $99.8(5559 / 5571)$ & 4 & 8 & $0(0 / 12)$ \\
\hline Gentamicin & $\leq 0.5$ & 2 & $90.5(5043 / 5571)$ & $\leq 0.5$ & 32 & $75.0(9 / 12)$ \\
\hline Meropenem & $\leq 0.06$ & $\leq 0.06$ & $100.0(5570 / 5571)$ & $\leq 0.03$ & $\leq 0.03$ & $100.0(12 / 12)$ \\
\hline Piperacillin-tazobactam & 2 & 4 & $97.5(5434 / 5571)$ & $\leq 1$ & 4 & $100.0(12 / 12)$ \\
\hline Trimethoprim-sulfamethoxazole & $\leq 0.12$ & $>8$ & $72.6(4047 / 5571)$ & $\leq 0.12$ & $>8$ & $83.3(10 / 12)$ \\
\hline
\end{tabular}




\begin{tabular}{|lccccc|}
\hline $\begin{array}{l}\text { Table 3: Antimicrobial susceptibility profile for the } 2 \text { Escherichia coli isolates that tested positive for } \\
\text { MCR-1 }\end{array}$ & \multicolumn{2}{c|}{ Isolate from Ontario } & & \multicolumn{2}{c|}{ Isolate from British Columbia } \\
\cline { 2 - 5 } \cline { 5 - 6 } Antimicrobial & MIC, $\mu \mathrm{g} / \mathrm{mL}$ & Interpretation & & MIC, $\mu \mathrm{g} / \mathrm{mL}$ & Interpretation \\
\hline Amoxicillin-clavulanate & $>32$ & Resistant & & 4 & Susceptible \\
\hline Cefazolin & 8 & Resistant & 2 & Susceptible \\
\hline Ceftazidime & 0.5 & Susceptible & 0.5 & Susceptible \\
\hline Ceftriaxone & $\leq 0.25$ & Susceptible & $\leq 0.25$ & Susceptible \\
\hline Ciprofloxacin & $>16$ & Resistant & 0.5 & Susceptible \\
\hline Colistin & 16 & Resistant & 4 & Resistant \\
\hline Gentamicin & 32 & Resistant & $\leq 0.5$ & Susceptible \\
\hline Meropenem & $\leq 0.03$ & Susceptible & $\leq 0.03$ & Susceptible \\
\hline Piperacillin-tazobactam & 16 & Susceptible & 2 & Susceptible \\
\hline Trimethoprim-sulfamethoxazole & $>8$ & Resistant & $\leq 0.12$ & Susceptible \\
\hline
\end{tabular}

to an area where E. coli harbouring the $m c r-1$ gene are more commonly found.

\section{Interpretation}

MCR-1 was first described by Liu and colleagues ${ }^{7}$ among $E$. coli isolates in China in late 2015. They found the $m c r-1$ gene in E. coli from animals, raw meat samples and humans with clinical infection. There have subsequently been many publications documenting the widespread dissemination of this resistance determinant. ${ }^{23}$ The mor-1 gene has been detected in isolates recovered from animals in China, Japan, Vietnam, Malaysia, France, Germany, the Netherlands, Belgium, Italy, Spain, Tunisia and Algeria. ${ }^{23,24}$ Isolates harbouring the $m c r-1$ gene have been found in food products (mostly meat) in the Netherlands, Portugal, Denmark, France, Switzerland, the United Kingdom, China and Taiwan. ${ }^{23,25}$ In addition, clinical isolates that contain the mor-1 gene have been reported in Vietnam, China, Taiwan, Thailand, Laos, Cambodia, the Netherlands, Sweden, the UK, Germany, Denmark, Switzerland, Italy, South Africa, Egypt, Argentina and the United States. ${ }^{23,25-30}$ Of interest, Shen and colleagues ${ }^{31}$ showed the presence of $m o r-1$ in 3 E. coli isolates of chicken origin from China dating back to the 1980s, which supports the view that this is not a new resistance mechanism despite its recent recognition. The $m c r-1$ gene has been found most commonly in $E$. coli but has also been detected in Salmonella spp. and K. pneumoniae. , $12,23,24^{2}$

Mulvey and colleagues ${ }^{32}$ have previously reported on the presence of the $m c r-1$ gene among E. coli in Canada. They screened about 1600 isolates from Canadian sources and identified $3 \mathrm{E}$. coli isolates that were $m c r-1$-positive: 1 was recovered from a clinical specimen in 2011, and 2 were recovered from lean ground beef in 2010. These findings as well as the data presented in the current study support the rarity of this resistance determinant in Canada at present. The 2 multilocus sequence types of the isolates that we identified (ST648 and ST515) were not closely related to the 3 reported by Mulvey and colleagues. 32
In the present study, both $E$. coli isolates with the $m c r-1$ gene were recovered from patients seen at hospital emergency departments, which implies community onset of infection. Because details regarding the clinical history of the patients were not available, it is impossible to determine whether the isolates were community-acquired or hospital-acquired. It is also not known whether either patient had a history of travel to a country where $E$. coli harbouring the $m c r-1$ gene are more prevalent. Given these limitations and the small number of $m$ cr-1-positive isolates in this study, no definitive conclusions can be drawn about whether this resistance mechanism may be more commonly found among $E$. coli isolates acquired in the community.

Colistin has been widely used in veterinary medicine for infections caused by Enterobacteriaceae in animals consumed as food. ${ }^{33}$ The detection of E. coli with the $m c r-1$ gene in a higher proportion of animal and raw meat samples relative to human clinical samples supports the notion that this resistance mechanism likely emerged in animals and subsequently spread to humans. It is speculated that the relative infrequency of $m c r-1$ among $E$. coli in Canada may relate to lower use of colistin among livestock in this country. ${ }^{34}$

\section{Limitations}

There are several important limitations to our study. Only E. coli isolates that tested phenotypically resistant to colistin were assessed for the presence of the $m c r-1$ gene. In the literature, E. coli that harbour $m c r-1$ typically have colistin MIC values of $4 \mu \mathrm{g} / \mathrm{mL}$ or greater. However, infrequently, this gene has been detected among isolates with an MIC of $2 \mu \mathrm{g} / \mathrm{mL} .{ }^{8} \mathrm{It}$ is possible that a very small number of $m c r-1$-positive isolates may have been missed by restricting testing to the colistinresistant subset, although this is unlikely. We did not evaluate the isolates for other mechanisms of colistin resistance. Hence, it is not known whether the phenotypic expression of colistin resistance among the isolates that tested positive for $m o r-1$ was entirely due to this resistance mechanism. We also did not determine the mechanism of colistin resistance among the 10 colistin-resistant isolates that did not contain the mor-1 
or $m c r-2$ genes. Data were not available for 2011, as colistin was not included on the susceptibility panel during that year. Finally, members of the family Enterobacteriaceae other than E. coli were not included in this analysis.

\section{Conclusion}

Colistin resistance was infrequent among $5571 \mathrm{E}$. coli clinical isolates obtained from patients at Canadian hospitals between 2008 and 2015. The proportion of E. coli isolates resistant to colistin varied from $0.0 \%$ to $0.5 \%$ depending on the study year, and there was no clear trend toward increasing resistance over time. Only 2 isolates were found to harbour the $m c r-1$ gene, and the $m c r-2$ gene was not detected in any of the isolates. These findings suggest that colistin resistance among E. coli clinical isolates, including resistance mediated by the $m c r-1$ gene, remains rare in Canada at present.

\section{References}

1. Falagas ME, Kasiakou SK. Colistin: the revival of polymyxins for the management of multidrug-resistant gram-negative bacterial infections. Clin Infect Dis 2005;40:1333-41.

2. Lim LM, Ly N, Anderson D, et al. Resurgence of colistin: a review of resistance, toxicity, pharmacodynamics, and dosing. Pharmacotherapy 2010;30:1279-91.

3. Nordmann P, Cuzon G, Naas T. The real threat of Klebsiella pneumoniae carbapenemase-producing bacteria. Lancet Infect Dis 2009;9:228-36.

4. Kumarasamy KK, Toleman MA, Walsh TR, et al. Emergence of a new antibiotic resistance mechanism in India, Pakistan, and the UK: a molecular, biological, and epidemiological study. Lancet Infect Dis 2010;10:597-602.

5. Falagas ME, Rafailidis PI, Matthaiou DK. Resistance to polymyxins: mechanisms, frequency and treatment options. Drug Resist Updat 2010;13:132-8.

6. Olaitan AO, Morand S, Rolain JM. Mechanisms of polymyxin resistance: acquired and intrinsic resistance in bacteria. Front Microbiol 2014;5:643.

7. Liu YY, Wang Y, Walsh TR, et al. Emergence of plasmid-mediated colistin resistance mechanism MCR-1 in animals and human beings in China: a microbiological and molecular biological study. Lancet Infect Dis 2016;16:161-8.

8. Grami R, Mansour W, Mehri W, et al. Impact of food animal trade on the spread of $m c r-1$ mediated colistin resistance, Tunisia, July 2015. Euro Surveill 2016;21. DOI: 10.2807/1560-7917.ES.2016.21.8.30144.

9. Doumith M, Godbole G, Ashton P, et al. Detection of the plasmid-mediated mor-1 gene conferring colistin resistance in human and food isolates of Salmonella enterica and Escherichia coli in England and Wales. 7 Antimicrob Chemother 2016;71:2300-5.

10. Malhotra-Kumar S, Xavier BB, Das AJ, et al. Colistin-resistant Escherichia coli harbouring $m c r-1$ isolated from food animals in Hanoi, Vietnam. Lancet Infect Dis 2016;16:286-7.

11. Prim N, Rivera A, Rodriguez-Navarro J, et al. Detection of $m c r-1$ colistin resistance gene in polyclonal Escherichia coli isolates in Barcelona, Spain, 2012 to 2015. Euro Surveill 2016;21. DOI: 10.2807/1560-7917.ES.2016.21.13.30183.

12. Du H, Chen L, Tang YW, et al. Emergence of the $m c r-1$ colistin resistance gene in carbapenem-resistant Enterobacteriaceae. Lancet Infect Dis 2016;16:287-8.

13. Yao X, Doi Y, Zeng L, et al. Carbapenem-resistant and colistin-resistant Escherichia coli co-producing NDM-9 and MCR-1. Lancet Infect Dis 2016;16:288-9.

14. Haenni M, Poirel L, Kieffer N, et al. Co-occurrence of extended spectrum $\beta$ lactamase MCR-1 encoding genes on plasmids. Lancet Infect Dis 2016;16:281-2.

15. Falgenhauer L, Waezsada SE, Yao Y, et al.; RESET consortium. Colistin resistance gene $m c r-1$ in extended-spectrum $\beta$-lactamase-producing and carbapenemase-producing Gram-negative bacteria in Germany. Lancet Infect Dis 2016;16:282-3.

16. Xavier BB, Lammens C, Ruhal R, et al. Identification of a novel plasmidmediated colistin-resistance gene, mor-2, in Escherichia coli, Belgium, June 2016. Euro Surveill 2016;21. DOI: 10.2807/1560-7917.ES.2016.21.27.30280.

17. M07-A-10: Methods for dilution antimicrobial susceptibility tests for bacteria that grow aerobically; approved standard. 10th ed. Wayne (PA): Clinical and Laboratory Standards Institute; 2015.

18. Recommendations for reference MIC-testing of colistin. Basel (Switzerland): European Committee on Antimicrobial Susceptibility Testing; 2016. Available: www.eucast.org/fileadmin/src/media/PDFs/EUCAST files/General documents/ Recommendations_for_MIC_determination_of_colistin_March_2016.pdf (accessed 2016 Sept. 11).

19. M100S: performance standards for antimicrobial susceptibility testing. 26th ed. Wayne (PA): Clinical and Laboratory Standards Institute; 2016.
20. Breakpoint tables for interpretation of MICs and zone diameters. Version 6.0. European Committee on Antimicrobial Susceptibility Testing; 2016. Available: www.eucast.org/fileadmin/src/media/PDFs/EUCAST_files/Breakpoint_tables/ v 6.0 Breakpoint table.pdf (accessed 2016 May 9).

21. Mangat CS, Boyd D, Janecko N, et al. Characterization of VCC-1, a novel Ambler Class A carbapenemase from Vibrio cholerae isolated from imported retail shrimp sold in Canada. Antimicrob Agents Chemother 2016;60:1819-25.

22. German GJ, Jamieson FB, Gilmour M, et al. Interim recommendations for the reporting of extensively drug resistant and pan-drug resistant isolates of Enterobacteriaceae, Pseudomonas aeruginosa, Acinetobacter spp. and Stenotrophomonas maltophilia. Can Commun Dis Rep 2016;42-4:91-7.

23. Skov RL, Monnet DL. Plasmid-mediated colistin resistance ( $m c r-1$ gene) three months later, the story unfolds. Euro Surveill 2016;21. DOI: 10.2807/ 1560-7917.ES.2016.21.9.30155.

24. Quesada A, Ugarte-Ruiz M, Iglesias MR, et al. Detection of plasmid-mediated colistin resistance (MCR-1) in Escherichia coli and Salmonella enterica isolated from poultry and swine in Spain. Res Vet Sci 2016;105:134-5.

25. Kuo SC, Huang WC, Wang HY, et al. Colistin resistance gene mor-1 in Escherichia coli isolates from humans and retail meats, Taiwan. 7 Antimicrob Chemother 2016;71:2327-9.

26. Coetzee J, Corcoran C, Prentice E, et al. Emergence of plasmid-mediated colistin resistance (MCR-1) among Escherichia coli isolated from South African patients. SAfr Med 7 2016;106:35-6.

27. Cannatelli A, Giani T, Antonelli A, et al. First detection of $m c r-1$ colistin resistance gene in Escherichia coli in Italy. Antimicrob Agents Chemother 2016;60:3257-8.

28. Elnahriry SS, Khalifa HO, Soliman AM, et al. Emergence of plasmid-mediated colistin resistance gene $m c r-1$ in a clinical Escherichia coli isolate from Egypt. Antimicrob Agents Chemother 2016;60:3249-50.

29. Rapoport M, Faccone D, Pasteran F, et al.; MCR Group. First description of mor-1-mediated colistin resistance in human infections caused by Escherichia coli in Latin America. Antimicrob Agents Chemother 2016;60:4412-3.

30. McGann P, Snesrud E, Maybank R, et al. Escherichia coli harboring mor-1 and $b l a_{\text {Стх. }}$ on a novel IncF plasmid: first report of $m o r-1$ in the USA [published erratum in Antimicrob Agents Chemother 2016;60:5107]. Antimicrob Agents Chemother 2016;60:4420-1

31. Shen Z, Wang Y, Shen Y, et al. Early emergence of $m o r-1$ in Escherichia coli from food-producing animals. Lancet Infect Dis 2016;16:293.

32. Mulvey MR, Mataseje LF, Robertson J, et al. Dissemination of the $m c r-1$ colistin resistance gene. Lancet Infect Dis 2016;16:289-90.

33. Catry B, Cavaleri M, Baptiste K, et al. Use of colistin-containing product within the European Union and European Economic Area (EU/EEA): development of resistance in animals and possible impact on human and animal health. Int 7 Antimicrob Agents 2015:46:297-306.

34. Van Boeckel TP, Brower C, Gilbert M, et al. Global trends in antimicrobial use in food animals. Proc Natl Acad Sci US A 2015;112:5649-54.

Affiliations: Section of Infectious Diseases (Walkty), Department of Internal Medicine; Department of Medical Microbiology (Walkty, Karlowsky, Adam, Lagacé-Wiens, Baxter, Zhanel), University of Manitoba; Diagnostic Services Manitoba (Walkty, Karlowsky, Adam, Lagacé-Wiens); Public Health Agency of Canada (Mulvey, McCracken), Winnipeg, Man.; Department of Microbiology (Poutanen), University Health Network/Mount Sinai Hospital; Departments of Laboratory Medicine and Pathobiology and of Medicine (Poutanen), University of Toronto, Toronto, Ont.; Department of Microbiology (Roscoe), Vancouver Hospital, Vancouver, BC

Contributors: Susan Poutanen and Diane Roscoe were involved in collecting the isolates. George Zhanel and Heather Adam were involved in designing the CANWARD study and obtaining isolates. Michael Mulvey and Melissa McCracken were involved in the molecular analysis of the isolates. James Karlowsky, Philippe Lagacé-Wiens, Andrew Walkty and Melanie Baxter were involved in data analysis. Andrew Walkty interpreted the data and drafted the manuscript. All of the authors were involved in revising the manuscript, approved the final version to be published and agreed to act as guarantors of the work.

Funding: The CANWARD study was supported in part by Astellas Pharma, Bayer, Cerexa/Forest Laboratories, Cubist Pharmaceuticals, Merck, Paladin Labs, Pfizer/Wyeth, Sunovion Pharmaceuticals and The Medicines Company. The opinions, results and conclusions reported in this article are those of the authors and are independent from the funding sources.

Supplemental information: For reviewer comments and the original submission of this manuscript, please see www.cmajopen.ca/content/4/47 E641/supp1/DC1 